\title{
Green Tea Extract Induces Apoptosis in the AGS Gastric Carcinoma Cell Line
}

\section{Fernando Gonzalez*}

Department of Microbiology and Immunology, Arizona College of Osteopathic Medicine, Midwestern University, USA

\begin{abstract}
Green tea has long been thought to possess anticancer properties. Additionally, the polyphenol components of green tea have demonstrated ability to inhibit $26 \mathrm{~S}$ proteasome function. As there have been reports describing varied responses of gastric carcinoma cells to green tea treatment, the role of green tea treatment on proteasome function in the gastric carcinoma cell line AGS was investigated. Presented here are findings demonstrating that green tea extract is capable of inhibiting proteasome function of AGS cells. Furthermore, treatment of AGS cells with the green tea polyphenol (-)-Epigallocatechin-3-gallate resulted in a similar level of proteasome inhibition. It was also discovered in this study that proteasome inhibition in AGS cells resulted in a buildup of Kip1/p27 and $\mathrm{I}_{\kappa} \mathrm{B} \alpha$, proteins that are involved in the progression through the G1/S checkpoint during cell division. Proteasome inhibition by (-)-Epigallocatechin3-gallate led to induction of apoptosis of AGS cells. Our results described here strongly suggest that green tea consumption is capable of inducing programmed cell death in gastric carcinoma cells through inhibition of proteasome activity. It should be noted, however, that consumption of green tea during anti-cancer protocols has been reported to reduce the effectiveness of a specific subset of chemotherapeutic compounds. In summary, consumption of green tea in gastric carcinoma patients may be effective in targeting cancer cells and slowing the progression of gastric cancers. Future studies of these natural products may provide some structural information which will allow for the development of the next generation of anti-cancer chemotherapeutics.
\end{abstract}

Keywords: Green tea; Proteasome; Gastric carcinoma; Apoptosis

\section{Introduction}

Green tea has long been consumed worldwide, and numerous reports have provided evidence of the beneficial nutritional aspects of green tea [1]. More specifically, epidemiological studies have provided correlative evidence that consumption of green tea reduces cancer development [2]. Additionally, green tea extracts have been found to possess anti-tumor activity in animal models and cultured cells $[3,4]$. Effects on tumors and cancer cells have been attributed to the polyphenol compounds contained within green tea extracts [5-7]. The catechin (-)-Epigallocatechin-3-gallate (EGCG) is thought to be the most potent of the polyphenol components, and has been shown to mediate an induction of an apoptotic cascade in certain tumor cells [8-10]. Varying degrees of tumor cell inhibition have been reported, however, depending both on cell lines studied [11] and also which catechins were used as inhibitors [12].

Nam, et al. [13] demonstrated that the polyphenols were capable of inhibiting the activity of the $26 \mathrm{~S}$ proteasome complex. The $26 \mathrm{~S}$ proteasome is a large multi-protein complex that regulates many cellular metabolic processes through protein degradation of ubiquitinylated target proteins [14]. Processes ranging from protein sorting [15] to peptide presentation in immune system functions [16] are regulated by proteasome function. Recent reports have also demonstrated that the proteasome is a dynamic complex that influences processes such as activated transcription [17-20] and DNA repair [21-23] solely through the action of a non-proteolytic proteasome sub-complex known as the $19 S$ regulatory complex. Interestingly, among other proteasomeregulated cellular processes are apoptosis and progression through the cell division cycle $[24,25]$. Cyclin Dependent Kinases (CDK) inhibitor proteins such as Kip1/p27 must be degraded by the proteasome in order for the cell to proceed through the G1/S checkpoint [26]. Failure to degrade these proteins in a temporal fashion has been shown to trigger apoptosis in a variety of cell types [26]. Progression from mitosis also relies on the temporal degradation of M-phase promoting cyclins [24], thus demonstrating the importance for proper proteasome function in "normal" cellular function.
Inhibition of proteasome activity has long been thought to be an attractive method by which to target cancer cells. The compound bortezomib (Velcade, Millennium Pharmaceuticals) was the first of such chemical proteasome inhibitors to be approved as an anticancer treatment [27]. Bortezomib therapy demonstrated effectiveness against multiple myeloma, but there are recent reports of association of bortezomib treatment and toxicity, as well as tumor cell types exhibiting resistance to the inhibitor [27]. The success of bortezomib has sparked an interest in the study of proteasome inhibitors as anticancer chemotherapeutics.

In this work, the effects of green tea extract and the polyphenol EGCG were studied in their ability to affect the growth of the AGS gastric adenocarcinoma cell line. It was found that incubation of AGS cells with either green tea extract or pure EGCG inhibited proteasome function, and led to the buildup of ubiquitinylated proteins to a similar extent as treatment of AGS cells with the proteasome inhibitor MG132. Use of purified human proteasome complexes further confirmed the inhibitory properties of EGCG. To evaluate cellular effects of EGCG-mediated proteasome inhibition, induction of apoptosis was studied. EGCG was found to induce apoptosis, and also to lead to a buildup of CDK inhibitor proteins involved in the progression from G1 to $S$ phase. Taken together these results suggest that EGCG, through its proteasome inhibiting properties, is capable of inducing apoptosis of AGS cells via cell cycle blockage at the G1/S border.

*Corresponding author: Fernando Gonzalez, Department of Microbiology and Immunology, Arizona College of Osteopathic Medicine, Midwestern University, 19555 N. 59 ${ }^{\text {th }}$ Avenue, Glendale, AZ 85308, USA, Tel: 623-572-3723; Fax: 623-572-3673; E-mail: fgonza@midwestern.edu

Received March 14, 2014; Accepted April 23, 2014; Published April 28, 2014

Citation: Gonzalez F (2014) Green Tea Extract Induces Apoptosis in the AGS Gastric Carcinoma Cell Line. Nat Prod Chem Res 2 :130. doi:10.4172/23296836.1000130

Copyright: ( 2014 Gonzalez F. This is an open-access article distributed under the terms of the Creative Commons Attribution License, which permits unrestricted use, distribution, and reproduction in any medium, provided the original author and source are credited. 


\section{Materials and Methods}

\section{Cell Line and Culture Conditions}

The human gastric carcinoma cell line AGS, culture medium, and supplements were obtained from American Type Culture Collection (ATCC, Manassas, VA) unless otherwise noted. Cells were cultured in Ham's F12K medium supplemented with $2 \mathrm{mM}$ final concentration L-glutamine and $10 \%$ Fetal Bovine Serum (Atlanta Biologicals, Flowery Branch, GA). Cultures were maintained at $37^{\circ} \mathrm{C}$ and $5 \% \mathrm{CO} 2$ during all experiments.

\section{Treatment of Gastric Carcinoma Cells with Green Tea Extract, EGCG, or the Proteasome Inhibitor MG-132}

For experiments that incorporated incubation of cells with chemicals, $1 \times 10^{6}$ cells were plated in a total of $3 \mathrm{ml}$ culture medium in 6 well culture plates. Each condition was plated in triplicate. Green tea extract (Pharmanex, Provo, UT) and epigallocatechin gallate (EGCG; Sigma-Aldrich, St. Louis, MO) were resuspended in sterile water, and the 26S proteasome inhibitor Z-Leu-Leu-Leu-CHO (MG-132, Enzo Life Sciences, Farmingdale, NY) was resuspended in dimethyl sulfoxide (DMSO; Sigma-Aldrich, St. Louis, MO). Inhibitors were incubated at the indicated concentrations for 1 hour prior to cell harvesting. Following the 1 hour time period, cells were washed twice in 1X Dulbecco's PBS (Life Technologies, Carlsbad, CA) and pellets were stored at $-80^{\circ} \mathrm{C}$. Whole cell extracts (WCE) were generated from cell pellets using the M-PER protein extraction reagent (Pierce Biotechnology, Rockford, IL) and protein concentrations were determined by bicinchoninic acid (BCA) protein quantitation (Pierce Biotechnology, Rockford, IL) on a spectrophotometer at $562 \mathrm{~nm}$.

\section{S Proteasome Assays}

Activity of the $26 \mathrm{~S}$ proteasome was assayed by measuring the chymotryptic activity of the complex. Briefly, $50 \mu \mathrm{g}$ WCE was prewarmed to $37^{\circ} \mathrm{C}$ along with $25 \mu \mathrm{l}$ assay buffer $(50 \mathrm{mM}$ Tris- $\mathrm{HCl}, \mathrm{pH}$ 7.5). Sterile water was used to bring the final reaction volume to $100 \mu$ l. The reaction was initiated upon the addition of $5 \mu \mathrm{l}$ of $0.5 \mathrm{mM}$ SuccinylLeucine-Leucine-Valine-Tyrosine-7-Amido-4-methylcoumarin (SuccLLVY-AMC; Bachem, Torrence, CA). Reactions were performed in triplicate and allowed to progress at $37^{\circ} \mathrm{C}$ for 2 hours. Fluorescence of liberated AMC corresponded to proteasomal peptidase activity and was measured in a BioTek Synergy2 microplate reader (BioTek US, Winooski, VT), using excitation wavelength of $340 \mathrm{~nm}$ and emission wavelength of $465 \mathrm{~nm}$.

For assays that tested in vitro inhibition of purified human $26 \mathrm{~S}$ proteasome, the proteasome complex was obtained from Boston Biochem (Cambridge, MA). Purified proteasome was added to a final concentration of $10 \mathrm{nM}$ to the assay components as described above. Green tea extract, EGCG, or MG-132 were added to intact proteasome complexes, and allowed to incubate on ice for 15 minutes prior to adding the fluorogenic substrate Succ-LLVY-AMC. Enzyme activity was measured as described above, and was reported as Relative Fluorescence Units (RFU).

\section{Western Blot Analysis}

Whole cell extracts generated from mock or inhibitor treated cell populations were used in western blot analyses. Fifty micrograms of total protein for each condition was loaded in SDS-PAGE gels and transferred to nitrocellulose membranes (BIORAD, Hercules, CA). Accumulation of ubiquitinylated proteins as a result of proteasome inhibition was observed using a primary antibody raised against ubiquitin (Boston Biochem, Cambridge, MA). Antisera raised against poly ADP ribose polymerase-1 (PARP-1), IкBa, Kip1/p27 and $\beta$-actin were obtained from EMD Millipore (Billerica, MA). Secondary antibodies conjugated to horseradish peroxidase were obtained from Pierce (Rockford, IL). Bands corresponding to the proteins of interest were visualized on autoradiography film (Phenix Research Products, Candler, NC) using the Supersignal Pico Western Blot Detection kit (Pierce Biotechnology, Rockford, IL).

\section{Caspase 3 Assay}

Induction of apoptosis was addressed by measuring the activation of caspase 3 in whole cell extracts either mock treated or treated with EGCG at various concentrations. Caspase 3 activity corresponded to the cleavage of the caspase 3 specific substrate Ac-Aspartic acidGlutamic acid-Valine-Aspartic acid-para-nitro aniline (Ac-DEVDpNA; EMD Millipore, Billerica, MA). Briefly, $200 \mu \mathrm{M}$ Ac-DEVD-pNA was incubated with $25 \mu \mathrm{g}$ total protein in $100 \mu \mathrm{l}$ buffer consisting of 50 mM HEPES, pH 7.4, $100 \mathrm{mM} \mathrm{NaCl}, 0.1 \%$ CHAPS, 10 mM DTT, 0.1 $\mathrm{mM}$ EDTA and $10 \%$ glycerol. Reactions were allowed to proceed for 2 hours at $37^{\circ} \mathrm{C}$, and 96 well plates were read at $405 \mathrm{~nm}$ on a BioTek Synergy 2 microplate reader (BioTek US, Winooski, VT). Reactions were each performed in triplicate, and the data reported represents the mean of measurements.

\section{Data Analysis}

Data was analyzed for significance using a one-way ANOVA and Dunnett's (2-sided) test in IBM SPSS. A p-value of less than 0.05 was considered to be significant.

\section{Results}

\section{Green tea extract inhibits 26 S activity in AGS cells}

Green and black tea extracts are known to possess polyphenol compounds that resemble traditional proteasome inhibitors such as $\beta$-lactone [13]. Using Jurkat T cells, Nam, et al [13] demonstrated that polyphenol components of green tea extracts possess significant proteasome inhibitory properties. Horie, et al [28] however presented data that demonstrated a gradient of effects by green tea catechins on different types of cultured cells. AGS cells were incubated with increasing concentrations of green tea extract in order to assess cellular responses to green tea extracts. Whole cell extracts from mock or green tea treated cells were subsequently generated and used in an assay of $26 \mathrm{~S}$ chymotrypsin-like proteasome activity. As shown in Figure 1A, incubation of AGS cells with crude green tea extract resulted in a concentration-dependent inhibition of the chymotrypsin-like activity of the proteasome. Interestingly, although there was no significant proteasome inhibition in cells treated with $20 \mu \mathrm{g} / \mathrm{ml}$ green tea extract, exposure of AGS cells to $80 \mu \mathrm{g} / \mathrm{ml}$ green tea extract resulted in approximately a $90 \%$ inhibition of $26 \mathrm{~S}$ proteasome activity.

The major anti-cancer compounds found in green tea extracts include the polyphenol catechin compounds, such as (-) epigallocatechin-3-gallate (EGCG; [29]). To address the ability of EGCG to specifically inhibit proteasome activity, AGS cells were incubated with different concentrations of pure EGCG (Figure 1B, black bars). As seen with cells exposed to green tea extract, cells treated with 80 $160 \mu \mathrm{M}$ EGCG exhibited significant levels of proteasome inhibition. Cells mock treated with water did not noticeably differ in the extent of AGS cell proteasome inhibition. As a source of comparison, AGS cells treated with the proteasome specific inhibitor MG-132 (Figure $1 \mathrm{~B}$, cross-hatched bars) demonstrated a similar pattern of inhibition of proteasomal chymotrypsin-like activity. 
A.

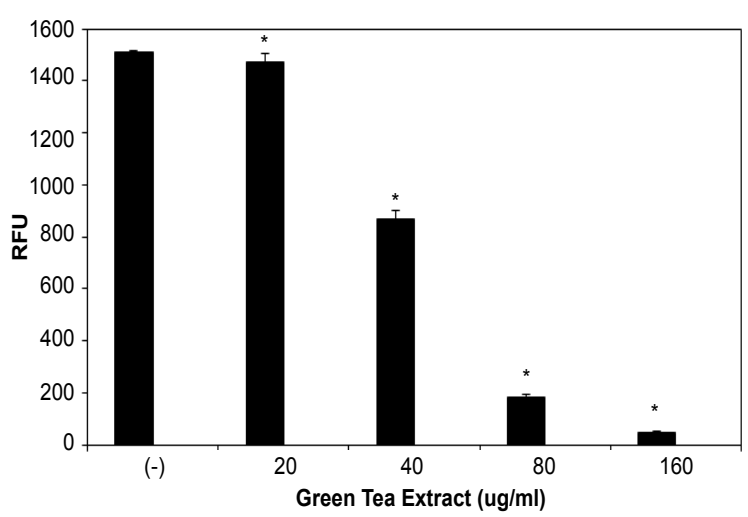

B.

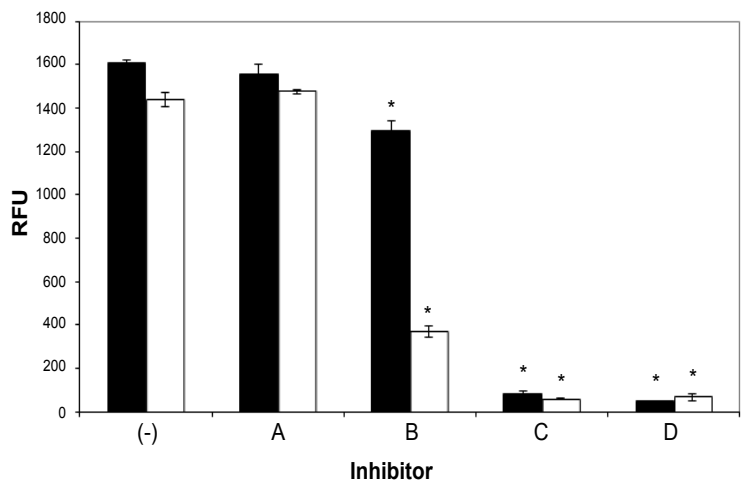

Figure 1: Proteasome inhibition by green tea extract. AGS cells were incubated with different concentrations of green tea extract for 1 hour prior to harvesting. Whole cell extracts were generated from mock-treated (-) or green tea extract-treated cell pellets, and $50 \mu \mathrm{g}$ of each extract was used to assess $26 \mathrm{~S}$ proteasome activity on the fluorogenic substrate Succ-LLVY-AMC. Fluorescence measurements were made 2 hours following substrate addition and are reported as Relative Fluorescence Units (RFU). Reactions were performed in triplicate and the data represents the mean of the measurements. Samples denoted with an asterisk $\left({ }^{*}\right)$ display a significant difference $(p<0.05)$ when compared to the control group. B) AGS cells were incubated with either EGCG (solid bars, $A=$ water control, $B=40 \mu \mathrm{M}, C=80 \mu \mathrm{M}, D=160 \mu \mathrm{M})$, or the proteasome inhibito MG-132 (cross-hatched bars, $A=D M S O$ control, $B=1 \mu M, C=5 \mu M, D=10 \mu M$ ) at varying concentrations prior to harvesting. Proteasome activity was addressed by measuring the increase in fluorescence through use of the substrate SuccLLVY-AMC, and results are reported as Relative Fluorescence Units (RFU). Reactions were performed in triplicate and results are reported as the mean of the 3 reactions. Samples denoted with an asterisk $\left(^{*}\right)$ display a significant difference $(p<0.05)$ when compared to the control group.

As the assay described above measures peptidase activity against a synthetic substrate, it was imperative to understand the influence of EGCG on proteasome function in AGS cells. Inhibition of proteasome function is known to result in the buildup of ubiquitinylated proteins in a whole cell extract [30]. Cells treated with either EGCG or MG132 was assessed for the relative quantity of ubiquitinylated proteins found in response to chemical treatment. As shown in Figure 2A, western blot analysis using an anti-ubiquitin primary antibody demonstrated a characteristic "smear" in untreated (-) or mocktreated (A) cell extracts. Incubation of AGS cells with increasing concentrations of EGCG demonstrated an increasing intensity of signal of ubiquitinylated proteins. Of interest was the finding that effects of EGCG treatment of AGS cells mimicked the cells treated with a specific chemical proteasome inhibitor (MG-132). Taken together, the results presented in Figures 1B and 2A demonstrate that EGCG inhibits gastric carcinoma cell proteasome function to an extent similar to the inhibition patterns of MG-132.

In order to specifically address the proteasome inhibitory properties of EGCG, a purified 26S proteasome complex was used in an assay as described above. Data shown in Figure 2B demonstrates that highly purified human $26 \mathrm{~S}$ proteasomes are also readily inhibited by EGCG. This data further suggests that the effects of green tea catechins function to target the proteasome complex.

\section{Proteasome inhibition in AGS cells results in induction of apoptosis}

Proteasome inhibition is known to efficiently induce apoptosis in cultured cells [30-32]. Additionally, anti-cancer chemotherapeutics such as bortezomib function to slow cancer cell growth through inhibition of proteasome activity. Based on the fact that both green tea extract and EGCG were capable of marked proteasome inhibition in cultured gastric carcinoma cells (AGS), it was hypothesized that proteasome inhibition would result in the induction of apoptosis in AGS cells. Whole cell extracts from AGS cells treated with EGCG concentrations known to inhibit proteasome activity were used in

A.
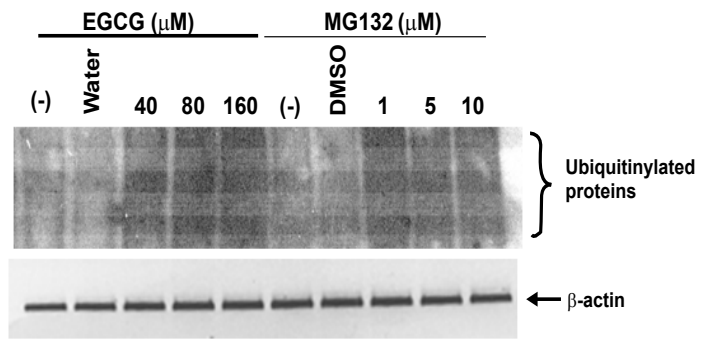

B.

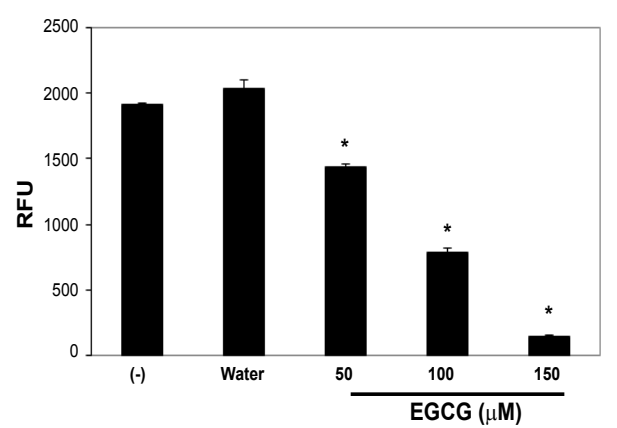

Figure 2: EGCG inhibits 26S proteasome activity. A) Accumulation of ubiquitinylated proteins was visualized by western blot analysis performed on mock (water) or treated whole cell extracts. Blots probed for presence of $\beta$-actin were used as a protein loading control. B) EGCG inhibition of purified human proteasomes was measured by cleavage of the substrate Succ-LLVY-AMC, and reported as Relative Fluorescence Units (RFU). Data represents the mean of 3 separate reactions for each treatment condition. Samples denoted with an asterisk $\left(^{*}\right)$ display a significant difference $(p<0.05)$ when compared to the control group. 
an assay for enzymatic activity of caspase 3 , a protein involved in the apoptotic pathway [33]. Data shown in Figure 3A demonstrates that incubation of AGS cells with increasing concentrations of EGCG resulted in the induction of caspase 3 activity.

To further address induction apoptosis by EGCG in AGS cells, whole cell extracts described above were used as the input proteins in western blot analyses. Blots were assayed for the presence of cleaved poly ADP ribose polymerase-1 (PARP-1), an indicator of irreversible, late stage apoptotic events $[34,35]$. As shown in Figure 3B, treatment of AGS cells with EGCG resulted in the cleavage of intact PARP-1 protein, as evidenced by the lack of detectable intact PARP-1 protein. Taken together, the results strongly suggest that proteasome inhibition in AGS cells by EGCG is capable of inducing programmed cell death of these cells.

A.

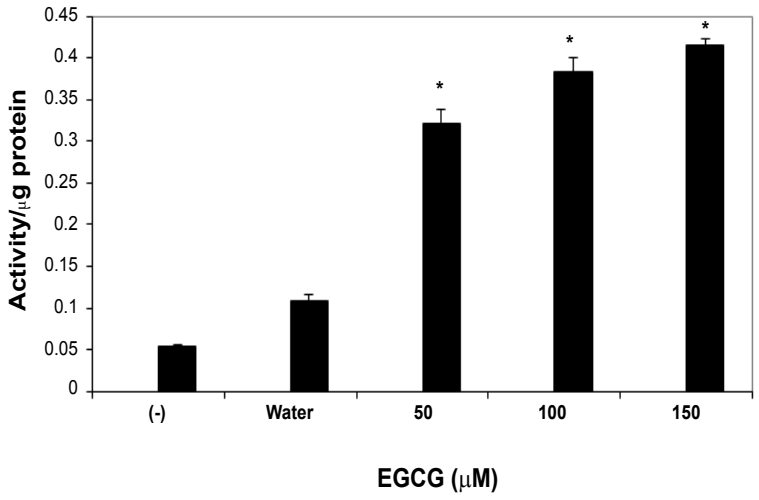

B.

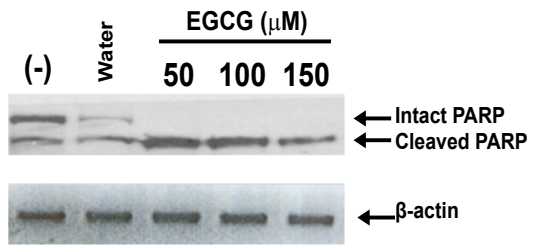

Figure 3: Proteasome inhibition by EGCG results in induction of apoptosis in AGS cells. AGS cells treated with various concentrations of EGCG were used to generate whole cell extracts. Activation of apoptosis in treated cells was visualized by: (A) induction of caspase 3 activity via colorimetric assay. Caspase 3 activity was initiated in EGCG-treated cell extracts as the cleavage of the caspase substrate DEVD-p-nitroaniline. Liberated p-NA chromophore was measured in at $405 \mathrm{~nm}$ on a BioTek Synergy2 microplate reader. Each reaction was performed in triplicate, and results are presented as activity/ug protein Samples denoted with an asterisk $\left({ }^{*}\right)$ display a significant difference $(p<0.05)$ when compared to the control group.

(B) cleavage of the PARP-1 protein. Mock (water) or EGCG-treated whole cell extracts were used in western blot analysis. PARP-1 cleavage was visualized as the processing of intact PARP-1 (116 kDa) to an inactive $86 \mathrm{kDa}$ fragment. Blots probed for presence of $\beta$-actin were used as a protein loading control.

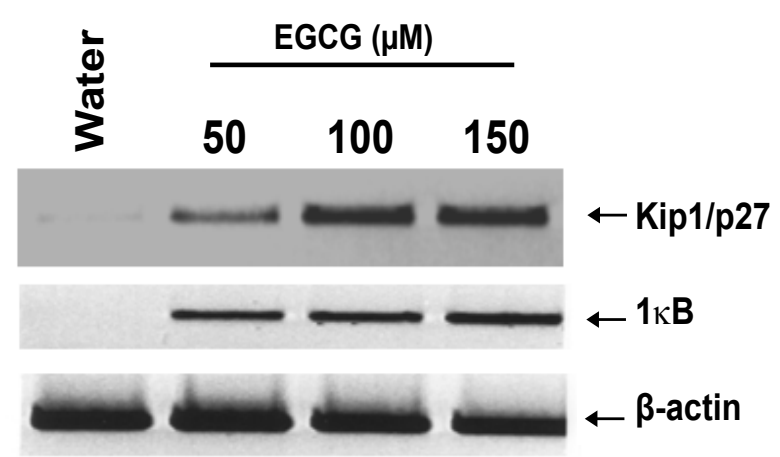

Figure 4: EGCG-mediated proteasome inhibition causes AGS cell cycle arrest at the G1/S border. Equal protein amounts were loaded into SDS-PAGE gels. Accumulation of the Cdk inhibitor Kip1/p27 and the transcription inhibitor $1 \kappa B \alpha$ was measured in mock (water) or EGCG-treated AGS cells through western blot analysis. Blots probed for presence of $\beta$-actin were used as a protein loading control.

\section{EGCG treated AGS cells are blocked at the G1/S border of the cell cycle}

Traditional chemical inhibition of proteasomes results in the arrest of cells at the G1/S checkpoint of the cell cycle. To further investigate the mechanistic role of EGCG-mediated proteasome inhibition in AGS cells, western blot analysis was performed in which 2 proteins involved in progression of cells through the G1/S border were investigated. Accumulation of the cyclin dependent kinase inhibitor Kip1/p27 and transcription inhibitor protein I $\mathrm{B} \alpha$ are hallmarks of cell cycle arrest at the G1/S checkpoint [36-38]. As evidenced in Figure 4, relative protein amounts of Kip1/p27 and IкBa were markedly increased in response to EGCG treatment, even at the lowest concentration of EGCG used experimentally $(50 \mu \mathrm{M})$. Little to no detectable Kip1/p27 or IкBa was observed in the mock treated samples (water). Additionally, antibodies raised against $\beta$-actin were used as a protein loading control. Results presented in Figure 4 strongly suggest that AGS cells exposed to EGCG are arrested at the G1/S border as a result of proteasome inhibition.

\section{Discussion}

Presented here is experimental evidence to support the longstanding idea that the chemical components of green tea possess anti-cancer cell properties. Using the gastric carcinoma cell line AGS, it was found that green tea extract was capable of inhibiting enzymatic activity of the $26 \mathrm{~S}$ proteasome. Coincidentally, a similar extent of proteasome inhibition was observed following treatment of AGS cells (and purified proteasomes) with the green tea polyphenol component (-)-Epigallocatechin-3-gallate (EGCG). Caspase activity assays provided evidence of apoptotic induction following exposure of AGS cells to EGCG. Furthermore, it was observed that EGCG mediated proteasome inhibition resulted in the accumulation of cell division cycle proteins involved in the release of cells from the G1/S border.

Epidemiological studies have provided correlative evidence to describe the association between green tea consumption and growth inhibition of tumors [1-4]. Subsequent work has attributed the majority of the anti-cancer effects of green tea to the polyphenol catechins found in green tea [39-41]. Furthermore, Nam, et al. [13] determined that concentrations of green tea catechins responsible for these effects lie close to, or at physiological levels found in green tea extracts. There are many proposed cellular effects following exposure to EGCG, including acting as an anti-oxidant in the scavenging of free oxygen radicals as 
well as acting to inhibit angiogenesis [42]. Interestingly, the proposed effect of polyphenols on regulation of the cell cycle machinery [24,25] may play the biggest role in inhibition of cancer progression.

Dysregulation of the machinery involved in cell division is known to induce the formation of cancer cells [32], and temporal degradation of proteins is necessary for proper progression through the cell division cycle [32]. Regulation of the cell division cycle proteins is largely a function of the $26 \mathrm{~S}$ proteasome, a multi subunit complex responsible for the majority of the non-lysosomal protein degradation in eukaryotes [14]. Coincidentally, EGCG of green tea was found to potently inhibit the chymotrypsin-like enzymatic activity of the proteasome complex [13]. Consistent with this idea are the results found in this study. Both green tea extract and EGCG were found to significantly inhibit the proteasomal chymotrypsin-like activity in the AGS gastric carcinoma cell line. This inhibition reached levels similar to the wellcharacterized proteasome inhibitor MG-132 (Figure 1B). Of note in the work presented here is that a general accumulation of ubiquitinylated proteins was also found in AGS cells exposed to EGCG (Figure 2A). When taken together, our results suggest that EGCG treatment of AGS cells greatly reduces the overall proteasome function.

Green tea and EGCG induce apoptotic pathways in a variety of cell lines originally isolated from gastric tumors [28,42]. Horie et al [28] however presented evidence to demonstrate that different gastric carcinoma cell lines exhibited varied susceptibility to EGCG. Synthetic EGCG analog compounds have also demonstrated varied proteasome-inhibiting ability $[12,43]$. Results described in the present study demonstrate that inhibition of the proteasome complex induces cell cycle arrest at the G1/S border (Figure 4) and programmed cell death of AGS cells (Figure 3), suggesting that EGCG treatment of AGS cells mimics the global effects of proteasome inhibition by traditional inhibitor chemicals [30].

Proteasome inhibition has become an exciting target for the development of novel anti-cancer chemotherapeutics. The proteasome inhibitor bortezomib (Velcade, Millennium Pharmaceuticals) was approved in 2003 as a treatment option for multiple myeloma, and greatly increased the interest and research in the field of proteasome inhibition. Currently, bortezomib is being investigated for its ability to treat other types of cancers [44]. With respect to the findings reported here that EGCG results in apoptosis of gastric carcinoma cells, one might assume that a combination of bortezomib and EGCG (or green tea) would work synergistically to inhibit cancer cell growth. Recently however, Golden et al. [44] demonstrated that consumption of green tea unexpectedly reduces the therapeutic activity of bortezomib and other boronic acid-based inhibitors (MG-262 and PS-IX). Results described here and elsewhere underscore the need for a more thorough understanding of not only the interactions of potential inhibitor compounds with each other, but also the knowledge regarding the detailed responses of various cell types to proteasome inhibition.

\section{Acknowledgement}

The author would like to thank A. Zehrbach for assistance with statistical analysis. This work was made possible by intramural funds to FG by Midwestern University.

\section{References}

1. Koo MW, Cho $\mathrm{CH}$ (2004) Pharmacological effects of green tea on the gastrointestinal system. Eur J Pharmacol 500: 177-185

2. Yang CS, Maliakal P, Meng X (2002) Inhibition of carcinogenesis by tea. Annu
Rev Pharmacol Toxicol 42: 25-54

3. Gupta S, Ahmad N, Mohan RR, Husain MM, Mukhtar H (1999) Prostate cancer chemoprevention by green tea: in vitro and in vivo inhibition of testosteronemediated induction of ornithine decarboxylase. Cancer Research 59: 2115 2120 .

4. Gupta S, Ahmad N, Mukhtar H (1999) Prostate cancer chemoprevention by green tea. Semin Urol Oncol 17: 70-76.

5. Katiyar SK, Challa A, McCormick TS, Cooper KD, Mukhtar H (1999) Prevention of UVB-induced immunosuppression in mice by the green tea polypheno (-)-epigallocatechin-3-gallate may be associated with alterations in IL-10 and IL-12 production. Carcinogenesis 20: 2117-2124.

6. Katiyar SK, Matsui MS, Elmets CA, Mukhtar H (1999) Polyphenolic antioxidant (-)-epigallocatechin-3-gallate from green tea reduces UVB-induced inflammatory responses and infiltration of leukocytes in human skin. Photochem Photobiol 69: 148-153.

7. Yamane T, Takahashi T, Kuwata K, Oya K, Inagake M, et al. (1995) Inhibition of N-methyl-N'-nitro-N-nitrosoguanidine-induced carcinogenesis by (-)-epigallocatechin gallate in the rat glandular stomach. Cancer Res 55: $2081-$ 2084.

8. Saeki K, Kobayashi N, Inazawa Y, Zhang H, Nishitoh H, et al. (2002) Oxidationtriggered c-Jun N-terminal kinase (JNK) and p38 mitogen-activated protein (MAP) kinase pathways for apoptosis in human leukaemic cells stimulated by epigallocatechin-3-gallate (EGCG): a distinct pathway from those of chemically induced and receptor-mediated apoptosis. Biochem J 368: 705-720.

9. Hayakawa S, Kimura T, Saeki K, Koyama Y, Aoyagi Y, et al. (2001) Apoptosisinducing activity of high molecular weight fractions of tea extracts. Biosci Biotechnol Biochem 65: 459-462.

10. Hayakawa S, Saeki K, Sazuka M, Suzuki Y, Shoji Y, et al. (2001) Apoptosis induction by epigallocatechin gallate involves its binding to Fas. Biochem Biophys Res Commun 285: 1102-1106.

11. Tanaka S, Aizawa K, Katayanagi N, Tanaka O (1994) Flow cytometric analysis of early steps in development of adriamycin resistance in a human gastric cancer cell line. Jpn J Cancer Res 85: 86-92.

12. Smith DM, Wang Z, Kazi A, Li LH, Chan TH, et al. (2002) Synthetic analogs of green tea polyphenols as proteasome inhibitors. Mol Med 8: 382-392.

13. Nam S, Smith DM, Dou QP (2001) Ester bond-containing tea polyphenols potently inhibit proteasome activity in vitro and in vivo. J Biol Chem 276: $13322-$ 13330.

14. Baumeister W, Walz J, Zühl F, Seemüller E (1998) The proteasome: paradigm of a self-compartmentalizing protease. Cell 92: 367-380.

15. Rocca A, Lamaze C, Subtil A, Dautry-Varsat A (2001) Involvement of the ubiquitin/proteasome system in sorting of the interleukin 2 receptor beta chain to late endocytic compartments. Mol Biol Cell 12: 1293-1301.

16. Pickering AM, Koop AL, Teoh CY, Ermak G, Grune T, et al. (2010) The

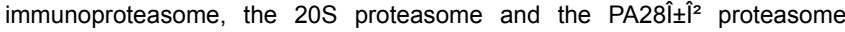
regulator are oxidative-stress-adaptive proteolytic complexes. Biochem $\mathrm{J} 432$ : 585-594.

17. Ferdous A, Gonzalez F, Sun L, Kodadek T, Johnston SA (2001) The 19S regulatory particle of the proteasome is required for efficient transcription elongation by RNA polymerase II. Mol Cell 7: 981-991.

18. Archer CT, Delahodde A, Gonzalez F, Johnston SA, Kodadek T (2008) Activation domain-dependent monoubiquitylation of Gal4 protein is essential for promoter binding in vivo. J Biol Chem 283: 12614-12623.

19. Gillette TG, Gonzalez F, Delahodde A, Johnston SA, Kodadek T (2004) Physica and functional association of RNA polymerase II and the proteasome. Proc Natl Acad Sci U S A 101: 5904-5909.

20. Gonzalez F, Delahodde A, Kodadek T, Johnston SA (2002) Recruitment of a $19 S$ proteasome subcomplex to an activated promoter. Science 296: 548-550.

21. Gillette TG, Huang W, Russell SJ, Reed SH, Johnston SA, et al. (2001) The 19S complex of the proteasome regulates nucleotide excision repair in yeast. Genes Dev 15: 1528-1539.

22. Gillette TG, Yu S, Zhou Z, Waters R, Johnston SA, et al. (2006) Distinct functions of the ubiquitin-proteasome pathway influence nucleotide excision repair. EMBO J 25: 2529-2538.

23. Reed SH, Gillette TG (2007) Nucleotide excision repair and the ubiquitin 
Citation: Gonzalez F (2014) Green Tea Extract Induces Apoptosis in the AGS Gastric Carcinoma Cell Line. Nat Prod Chem Res 2 :130. doi:10.4172/2329-6836.1000130

Page 6 of 6

proteasome pathway--do all roads lead to Rome? DNA Repair (Amst) 6: 149-156.

24. Hoyt MA (1997) Eliminating all obstacles: regulated proteolysis in the eukaryotic cell cycle. Cell 91: 149-151.

25. Hu X, Bryington M, Fisher AB, Liang X, Zhang X, et al. (2002) Ubiquitin/ proteasome-dependent degradation of D-type cyclins is linked to tumor necrosis factor-induced cell cycle arrest. J Biol Chem 277: 16528-16537.

26. Hershko A, Ciechanover A (1998) The ubiquitin system. Annu Rev Biochem 67: 425-479.

27. Voorhees PM, Dees EC, O'Neil B, Orlowski RZ (2003) The proteasome as a target for cancer therapy. Clin Cancer Res 9: 6316-6325.

28. Horie N, Hirabayashi N, Takahashi Y, Miyauchi Y, Taguchi H, et al. (2005) Synergistic effect of green tea catechins on cell growth and apoptosis induction in gastric carcinoma cells. Biol Pharm Bull 28: 574-579.

29. Cheynier V (2005) Polyphenols in foods are more complex than often thought. Am J Clin Nutr 81: 223S-229S.

30. Fenteany G, Schreiber SL (1998) Lactacystin, proteasome function, and cell fate. J Biol Chem 273: 8545-8548.

31. Concannon CG, Koehler BF, Reimertz C, Murphy BM, Bonner C, et al. (2007) Apoptosis induced by proteasome inhibition in cancer cells: predominant role of the p53/PUMA pathway. Oncogene 26: 1681-1692.

32. DeMartino GN (2004) Proteasome inhibition: mechanism of action. J Nat Compr Canc Netw 2 Suppl 4: S5-9.

33. Salvesen GS (2002) Caspases and apoptosis. Essays Biochem 38: 9-19.

34. Wang H, Shimoji M, Yu SW, Dawson TM, Dawson VL (2003) Apoptosis inducing factor and PARP-mediated injury in the MPTP mouse model of Parkinson's disease. Ann N Y Acad Sci 991: 132-139.

35. Yu SW, Wang H, Dawson TM, Dawson VL (2003) Poly(ADP-ribose) polymerase-1 and apoptosis inducing factor in neurotoxicity. Neurobiol Dis 14 303-317.

36. Polyak K, Kato JY, Solomon MJ, Sherr CJ, Massague J, et al. (1994) p27Kip1, a cyclin-Cdk inhibitor, links transforming growth factor-beta and contact inhibition to cell cycle arrest. Genes Dev 8: 9-22.

37. Toyoshima H, Hunter T (1994) p27, a novel inhibitor of G1 cyclin-Cdk protein kinase activity, is related to $\mathrm{p} 21$. Cell 78: 67-74.

38. Guttridge DC, Albanese C, Reuther JY, Pestell RG, Baldwin AS Jr (1999) NF-kappaB controls cell growth and differentiation through transcriptional regulation of cyclin D1. Mol Cell Biol 19: 5785-5799.

39. Lambert JD, Lee MJ, Lu H, Meng X, Hong JJ, et al. (2003) Epigallocatechin-3 gallate is absorbed but extensively glucuronidated following oral administration to mice. J Nutr 133: 4172-4177.

40. Lambert JD, Yang CS (2003) Mechanisms of cancer prevention by tea constituents. J Nutr 133: 3262S-3267S.

41. Lambert JD, Yang CS (2003) Cancer chemopreventive activity and bioavailability of tea and tea polyphenols. Mutat Res 523-524: 201-8.

42. Chen D, Milacic V, Chen MS, Wan SB, Lam WH, et al. (2008) Tea polyphenols their biological effects and potential molecular targets. Histol Histopathol 23 487-496.

43. Zhang Q, Tang X, Lu Q, Zhang Z, Rao J, et al. (2006) Green tea extract and (-)-epigallocatechin-3-gallate inhibit hypoxia- and serum-induced HIF-1alpha protein accumulation and VEGF expression in human cervical carcinoma and hepatoma cells. Mol Cancer Ther 5: 1227-1238.

44. Golden EB, Lam PY, Kardosh A, Gaffney KJ, Cadenas E, et al. (2009) Green tea polyphenols block the anticancer effects of bortezomib and other boronic acid-based proteasome inhibitors. Blood 113: 5927-5937. 